\title{
The Development of Self-Regulation-Based Holistic Health Counseling Model to Improve College Students' Psychological Well-Being
}

\author{
Lucia Hernawati $^{1}$, DYP Sugiharto ${ }^{2}$, Edy Purwanto ${ }^{2}$, Awalya $^{2}$ \\ \{herna@unika.ac.id ${ }^{1}$, s_dyp@yahoo.com ${ }^{2}$, edy.purwanto@mail.unnes.ac.id ${ }^{3}$, \\ dmj.awalya@yahoo.com $\left.{ }^{4}\right\}$ \\ Psychology Faculty, Soegijapranata Catholic University ${ }^{1}$, Universitas Negeri Semarang ${ }^{2,3,4}$
}

\begin{abstract}
Students must adapt to campus life, including the academic pressure, peer pressure, and poor physical and mental condition due to various academic tasks. All of these issues have the potential to make college students having low state of psychological well-being. Self-regulation method as the novelty of this study was used to support holistic health counseling to improve the psychological well-being of college students. The purpose of this study was to design a holistic health counseling model which was based on self-regulation to help college students improve their psychological well-being. Formative evaluation techniques were carried out to evaluate the counseling model.Two experts and two practitioners participated in evaluating the counseling model. The revised counseling model was ready to test through an experiment. Futhermore, it could be used in wider tertiary education setting.
\end{abstract}

Keywords: psychological well-being, college students

\section{Introduction}

Students must adapt to campus life, including facing academic pressure, peer pressure, changed eating time caused by crowded college schedules, lack of sleep because of various tasks from the lecturers, and poor physical conditions due to physical and mental fatigue [1]

In addition, technology and the globalization era, on the one hand, make it easier for students to communicate with anyone because information can be accessed quickly from anywhere, but on the other hand, it also has negative impacts, including making students academically unproductive and often experiencing online bullying, expecting instant things, and lacking physical movement [2],[3]

Based on the results of previous studies [4], it is known that generally, students do not pass college life happily. They tend to have less psychologically well-being status. Generally they experience feelings of under pressure (stress) caused by too many assignments given by the lecturers; feelings of anxiety and panic because the tasks have not been completed at the due date; feeling headache because of pushing themselves to stay late at night to do assignments from lecturers; stomach ache due to irregular eating time, and being unable to develop harmonious social life with friends.

From the description above, it can be concluded that students are less happy, less able to develop themselves to the fullest or do not have adequate psychological well-being status because they are not fit physically (headache, stomach pain); mentally (stress, bully-victim); and socially (conflict with others). 
To improve happiness, psychological well-being during college life, students need to receive holistic health counseling services that are based on self-regulation. The selfregulation method can be seen as the novelty of this study. This study aims to develop a model of holistic health counseling which is based on self-regulation to improve the college students' psychological well-being.

\section{Methods}

\subsection{Procedure}

The development of a holistic health counseling model based on the self-regulation began with the search for journals and books that contained various information about (a) the phenomenon of life experienced specifically by students in Indonesia, especially in Semarang, which made students have an inadequate psychological well-being status because their lifestyle was unhealthy holistically; (b) the results of wellness counseling research that become the basis for developing a holistic health model, psychological well- being, and selfregulation in Indonesia and outside the country of Indonesia; (c) the relationship between the concept of wellness counseling and psychological well- being with the self-regulation method. Then, based on those various journals and books, a model of holistic health counseling which was based on the self-regulation was developed to improve the appropriate psychological well-being of college students.

\subsection{Data collection}

After reading the counseling model developed by the researcher, two experts (doctors in the field of guidance and counseling with interest in developing counseling models at Universitas Negeri Semarang) and two practitioners (counselors at Soegijapranata Catholic University's student counseling service) were asked to fill out a model of validation questionnaire. This questionnaire allowed experts and practitioners to give their evaluation with open questions.

There were eight sub-sections in open questions for experts, namely rational, vision-mission, goal, basic principal, support system, implementation procedure of holistic health counseling based on self-regulation, techniques, and evaluation-follow up. Meanwhile, the open questions for practitioners included four sub-sections, namely the usefulness of the counseling model to achive psychological well-being, the opportunities for implementing the model in college, the conformity with student needs, and the easiness of the model to be understood.

\subsection{Data analysis}

Formative evaluation technique was used to improve the effectiveness of the counseling model produced [5]. All inputs from experts and practitioners were summarised and used to improve the holistic health counseling model which is based on self-regulation. 


\section{Result and Discussion}

A college is a place where students get knowledge of both academically and nonacademically. Colleges must prepare a curriculum that is by their respective study programs and also provides guidance and counseling services that can equip students to excel in the academic field and be able to learn to live [6], [7]. Higher education must help students develop their potential to be able to live happily (achieve well-being, especially psychological well-being) [8],[9]

In college, health promotion needs to be done so that students get information about healthy lifestyle holistically (physically, mentally, socially) and strive for real behavior [10]. If students have a healthy holistic lifestyle and care about the physical-mental-social health, they will be more productive in the academic field. Furthermore, they can undergo their study more happily (psychological well-being). In fact, in the long term, a healthy community or a healthy academic community will be formed [11].

Holistic health counseling which is based on self-regulation to improve the psychological well-being of college students, which is then referred to as HHCBSRIPWBCS comes from a wellness counseling model developed by Myers \& Sweeney in 2008. It was initially originated from Adler's concept of individual psychology, which was understood as being indivisible (individual phenomena as a unitary). According to Adler, individuals cannot be understood only partially but must be as a whole. Adler believes that in nature human behavior is holistic, directed, correlates with one another, and has a specific purpose. This thinking influenced Myer \& Sweeney in developing wellness counseling [12]

Wellness aspects are being creative, coping, social, essential, and physical. Overall, these aspects are related to each other [12]. The term wellness is often interpreted as healthy. Furthermore, referring to the health concept of the World Health Organization (WHO), which is intended to be healthy, not only is the individual condition of being free from illness but more than that, it is physically-mentally-socially healthy which integrates holistically. In its implementation, the aspects of wellness are directed towards holistic health (physical-mentalsocial).

Efforts to achieve a healthy physical-mental-social situation holistically can be made through individual and group counseling methods. However, in the HHCBSRIPWBCS model, it refers to group counseling [12]. Group counseling is effective for college students to exchange ideas, teach each other, and achieve insight continously until adaptive behaviour changes occur [13]. Wellness counseling focuses on the strategy of understanding the counselee, finding obstacles to its development which causes physical or mental or social healthiness in part or in whole, and planning interventions to improve dysfunction and optimize the development of self-potential. In the application of wellness counseling, the counselee is taught and facilitated to direct all of his abilities, which include the creative, coping, social, essential, physical ability to maintain physical-mental-social health

The HHCBSRIPWBCS model includes the self-regulation method. It includes (a) forethought, awareness of the importance of holistic health, things that must be fulfilled in order to be able to live a holistic healthy life, and make plans for application of real behavior in order to live a holistic healthy life; (b) monitoring, in the form of activities to carry out planned arrangements; (c) evaluation, in the form of evaluation of planning and realization of the program. Forethought, monitoring, evaluation are carried out periodically on an ongoing basis. In this way, individuals from day to day will increasingly recognize themselves and be able to make plans which are more suitable for themselves. Thus a healthy holistic lifestyle will be formed. 
HHCBSRIPWBCS lasts 31 days which includes 9 counseling sessions. Each session goes through the phases of orientation, exploration, intervention, and termination; includes delivery activities of impartial information, assessment, teleological analysis, goal setting, as well as designing efforts to achieve goal setting, and implementing planning to form a healthy lifestyle [14]. The HHCBSRIPWBCS model can be seen in figure 1

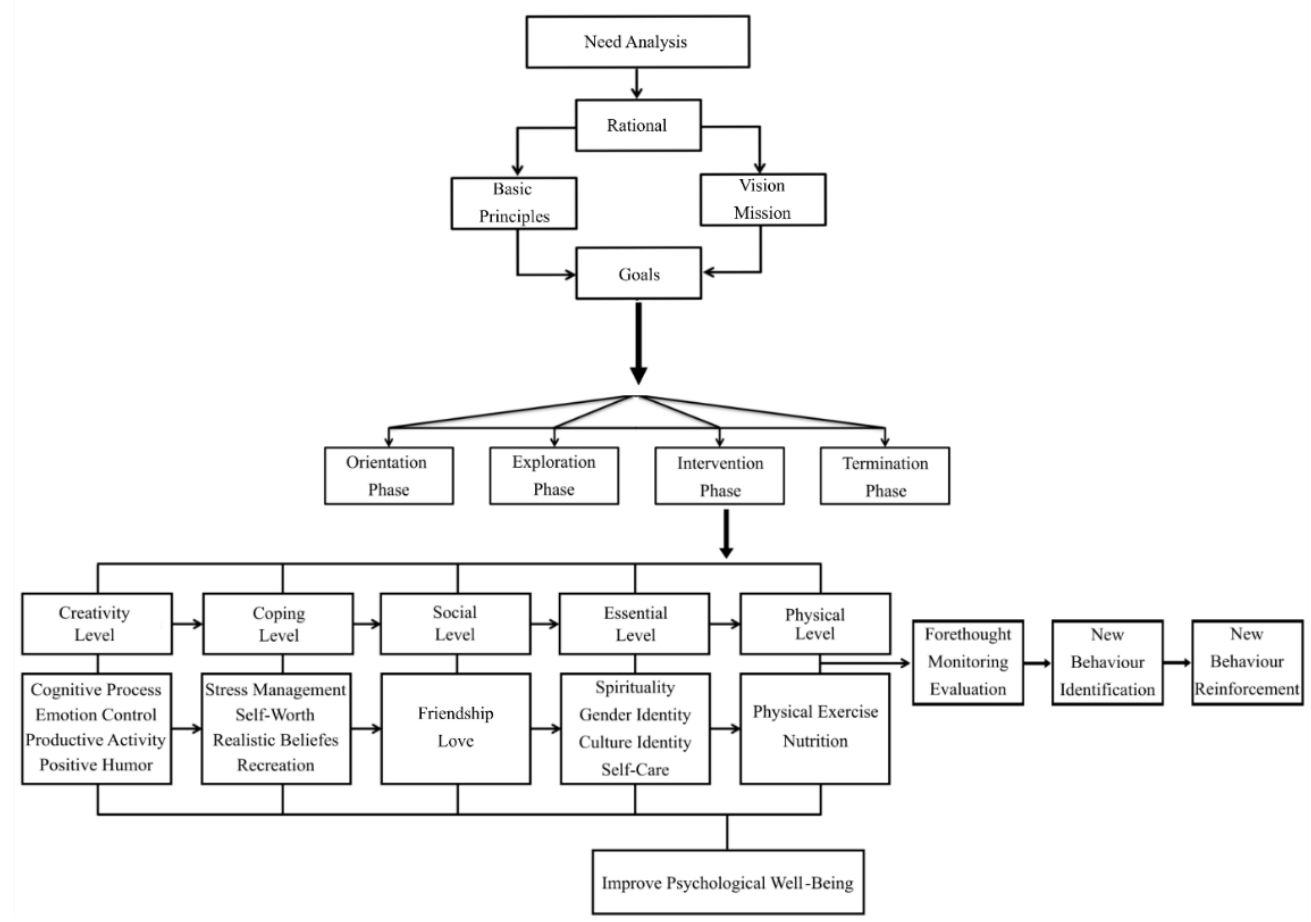

Figure 1. Holistic Health Counseling Based on Self-regulation Model to Improve Psychological WellBeing of College Students

The counseling model has received some input for improvement from experts and practitioners. The feedback from the experts and practitioners is needed by the researcher to improve the model developed [14]. The summaries of the inputs from experts and practitioners were as the following: (1) more detailed explanations about the concept and urgency of developing the model were needed; (2) more detailed explanation on the role of self-regulation in counseling were required; (3) four phases of counseling must be raised at each session; (4) an explanation of how the HHCBSRIPWBBCS could improve the counselle's better understanding of life's goals and self-development realization should be added; (5) an explanation that the 10 days follow up phase without guided counseling must be included.

All inputs from the experts and practitioners were used to improve the counseling model and its implementation. The revised version of the model can be seen in figure 2 . The revised model also shows the change of the role of self-regulation location and the four phases of counseling which must be raised at each session. 


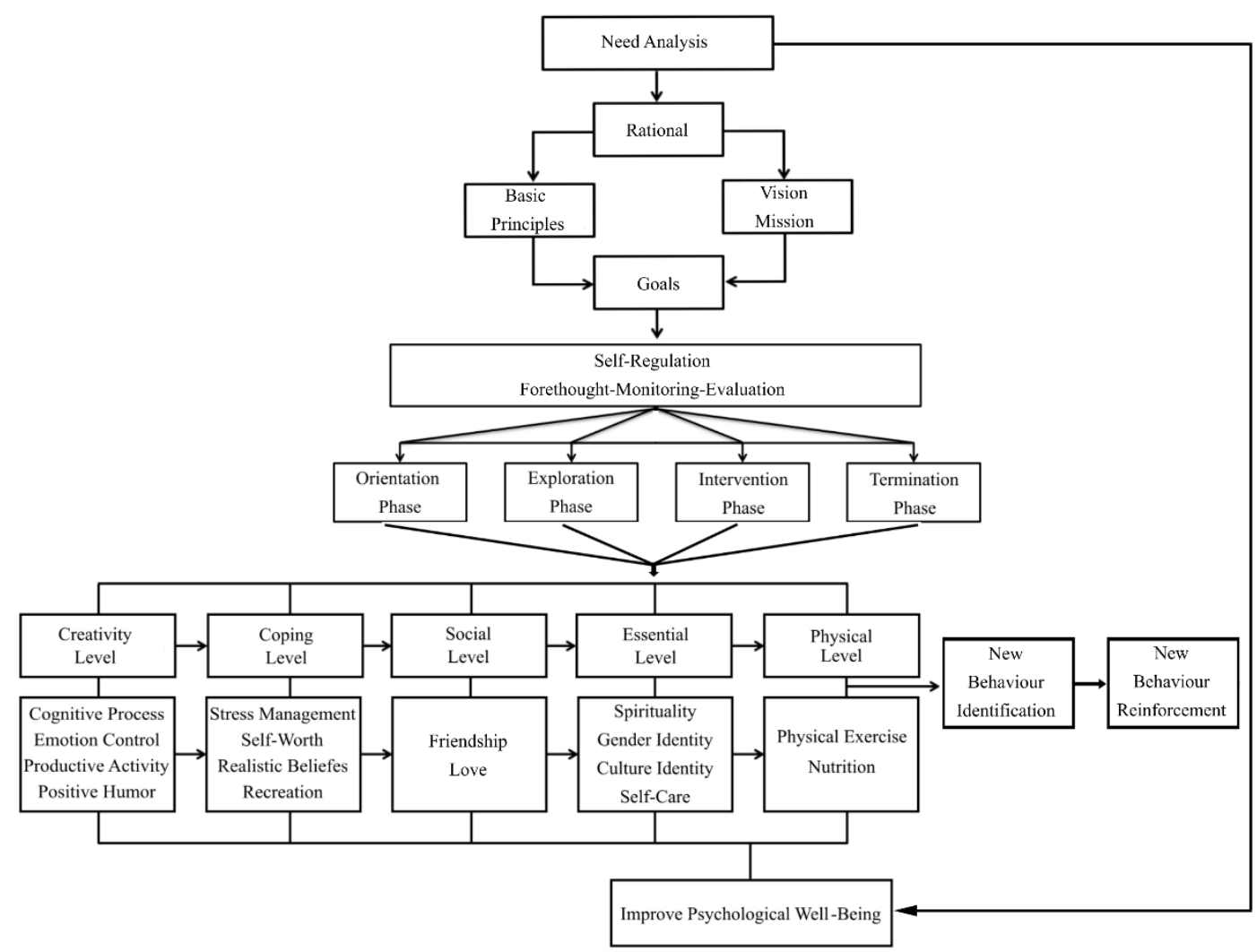

Figure 2. Holistic Health Counseling Based On Self-regulation Model to Improve Psychological Wellbeing of College Students (Revised)

\section{Conclusion}

The holistic health counseling model based on self-regulation to improve psychological well-being has been revised based on the input from experts and practitioners are ready to be tested in limited experiments on college students. It is expected that this counseling model can improve the psychological well- being of students. All input from the experiments will be useful to provide feedback on improving the counseling model. Further, it can be continued with the next experiments with a greater number of students coming from different universities. It is expected that this counseling model will be more perfect to improve the psychological condition of the college students. 


\section{References}

[1] Acaijas, C., Waldhausl, S., Lambert, N., Cassar, S., \& Corassa R.B : Determinants of Health-Related Lifetyles among University Students. Perspectives in Public Health, 137(4) 227-236 (2017)

[2] Cairns, S.L., Massfeller, H.F., \& Deeth, S.C: Why do Postsecondary Students Seek Counseling? Canadian Journal of Counseling 44(1)34-50. ISSN 0826-3893 (2010)

[3] Weiten, W., Lloyd, M.A., Dunn, Dana, S., Hammer, E.Y: Psychology Applied to Modern Life. Adjustment in The 21 St Century. pp.37-48 (2009).

[4] Hernawati, L. : The Relationship between Wellness and Self-Regulation with Psychological Well-Being among College Students in Semarang-Indonesia. Pp72-79 (2018)

[5] Purwanto, E. : Qualitative Research Methods. pp142-145 (2016).

[6] Gysbers, Norman, C \& Henderson, Patricia: Developing \& Managing Your School Guidance \& Counseling Program. Pp 235-247 (2012)

[7] Adebowale, T.A.:Perceived Availability of Guidance and Counseling Servis among Tertiary Institute Students in Selected South-West University in Nigeria. Life Psychology, 19(1)360-374 (2011)

[8] Lee, D., Oslon, E.A., Lock, B., Michelson, S.T \& Odes, E.:The Effects of College Counseling Services on Academic Performance and Retention. Journal of College Student Development, 50, 305-319.doi:10.1353/csd.0.0071.(2009)

[9] Pingree \& Harward.(2014). Bringing Theory to Practice. The Psychological Well-being and Flourishing of Students. pp 138-149 (2014).

[10] Weiss, L.A., Westerhof, G.J., Bahlmeijer. :Can We Increase Psychological Wellbeing? The Effect Of Interventions On Psychological PWB: A Meta Analysis of Randomized Controlled Trial. Journal Pone 11,6, 1-16 : e0158092. doi:10.13711.0158092 (2016)

[11] Hofer, J., Busch, H., \& Kartner, J. :Self-regulation and Well Beling: The Influence of Identity and Motives. European Journal of Personality 25, 211-224. doi:10.1002/per789 (2011).

[12] Myers J.E, \& Sweeney. T.J.: Wellness Counseling: The Evidence Base for Practice.Journal of Counseling and Development: JCD; 86,482-493 (2008).

[13] Mceneaney, A.M.S., Gross, J.M.: Introduction to the Special Issue: Group Intervention in College Counseling Centers, International Journal of Group Psychotherapy. Social Science Database, 59(4)455-460 (2009).

[14] Santos, S.D.: A Comprehensive Model for Developing and Evaluating Study Abroad Programs in Counselor Education. Int $\mathrm{J}$ Adv Counseling 36, 332-347. DOI 10.1007/s10447-014-9210-7 (2014). 